\section{Ozone depletion}

\section{Europe takes a cheerful view}

\section{Brussels}

Belgian scientists Guy Brasseur and A. de Rudder, of the Belgian Institute for Space Aeronomy, claim that the threat posed to the ozone layer by the release of chlorofluorocarbons (CFCs) from aerosols is "distant" and "that time can be allowed without risk for further scientific evaluation of theory". The result of their model calculation will strengthen European Community opposition to a proposed global ban on aerosols propelled by CFCs put forward by the United States at a meeting of the United Nations Environmental Programme on the ozone convention in Geneva at the end of January.

One distinctive feature of their calculations is that they have taken account of the probable growth of emission of gases other than CFCs that act as ozone buffers $(0.5$ per cent a year carbon dioxide, 1.0 per cent a year methane and 0.2 per cent nitrogen oxides). They have calculated the effect on ozone perturbation of constant CFC emissions, a global phase-out of CFCs in aerosols over four years with a 3 per cent growth rate in emissions from other uses until 1997 and the same scenario but with an indefinite 3 per cent growth rate.

According to their calculations, ozone depletion will occur only in the case that CFC emissions grow by 3 per cent a year after an aerosol ban, and would not happen before the year 2034. But the imposition of a production capacity ceiling or "cap", coupled with an attempt to limit stratospheric chlorine, would lead to an actual increase of total ozone. From this, the two scientists have concluded that there is no call for an immediate ban which, they say, would achieve little over and above the considerable protection conferred by a production capacity cap.

Their findings back up present Community measures which involve a production capacity cap up to 480,000 tonnes of CFCs decided in 1980, corresponding to one and a half times the production quantity at the time, and an agreement among member states to reduce the use of CFCs as propellants in aerosols by 30 per cent on 1976 levels, which came into force in 1981. According to the European Commission, the 36 per cent level was reached in 1984 .

Ministers had also agreed to monitor other uses of CFCs, in foam plastics, refrigeration, air conditioning and solvents, for which codes of practice have just been published by the European Commission.

The Community's approach to the problem of limiting CFC emissions, which has the support of the European chemical industry, is not, however, shared by such countries as the United States, which says the Community's proposal does not reduce emissions in the near term and is "tantamount to postponing action". It does not limit imports of CFCs or products con- taining them, while provisions to exempt developing countries, as CFCs become more and more essential to their needs, will, according to the United States, result in undesirable CFC emission levels. The United States also maintains that the Community's proposal will entail economic penalties once the production cap has been reached and the use of other products, for which no safe substitutes exist, will have to be limited. Among the other uses is air conditioning, which is far more common in the United States than elsewhere.

The US Environmental Protection Agency (EPA) reckons that strict limits on non-essential aerosols (which are estimated to account for 36 per cent of total CFC emissions) will delay the Community production cap by 13 years and will slow down emission. European scientists, on the other hand, have calculated that the positive effect of a ban on the ozone depletion rate as proposed by the United States would probably be not more than about 0.2 per cent a year. Last month a group of countries known as the Toronto Group led by the United States presented their draft protocol on limiting CFCs which they would like to see laid down in the ozone convention due to be signed in Vienna in March.

\section{Brussels}

Members of the European Parliament are increasing pressure on the Commission to ban imports of frogs' legs into the Community in an attempt to put an end to the alleged inhumane methods of slaughter and unhygienic conditions in which frogs are killed, as they become a more popular feature of the European dinner table.

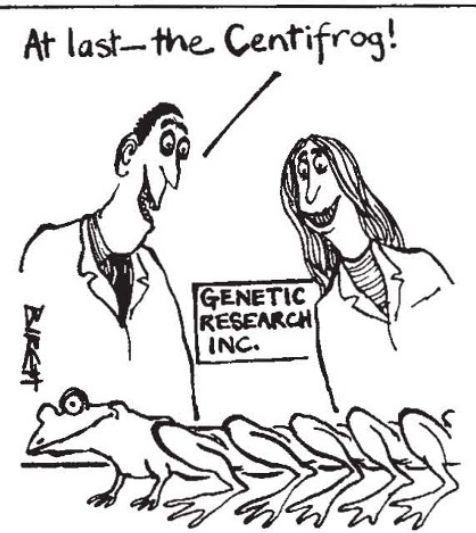

Imports of frogs' legs into the Community have been rising steadily over the past five years. In 1983, according to the European Commission, 6,022 tonnes (the equivalent of 15 million frogs) was imported, of which 2,517 tonnes came from Indonesia, 1,577 tonnes from Bangladesh and 1,274 tonnes from India. The French are the principal consumers,

Despite a distinct downward swing in computer modelling estimates of ozone depletion - depletion was estimated at 15-20 per cent in 1975 and at 2-4 per cent in 1984 - EPA projects remain gloomy. They put the new estimates down to a better understanding of the reactions among atmospheric gases but maintain that the increase of such gases as methane (and carbon dioxide) which act against ozone destruction will not be capable of stemming ozone depletion due to the considerable growth in CFCs. Unless action is taken, EPA expects an increase of between 1.4 and 4.2 per cent in CFC-propelled aerosols by 2075 . Because of the non-linear relationship between CFCs and ozone levels, this could mean, they say, a 26 per cent depletion of the ozone layer by that time.

The proposal, drafted by the United States, which banned the use of CFCs in aerosols in 1978, concentrates on a major global reduction in the use of CFCs as aerosol propellants. It provides four options to achieve this: phasing down the use of CFCs by 80 per cent over six years, a ban on all non-essential CFC-propelled aerosols, a 20 per cent reduction in all CFC use and a production capacity cap as well as a 70 per cent reduction in aerosols. Any of these, it is claimed, could reduce cumulative emissions of CFCs by 7,600 million kilograms by the year 2010 .

Anna Lubinska

\title{
European ban on frogs?
}

followed by the Benelux countries.

Apart from the inhumane way in which the frogs are killed, there is a risk of infection to consumers because of the delay between the killing and the packing in ice of the frogs' legs. Frogs are in any case natural pest controllers and in particular live off insects that may carry such diseases as malaria and encephalitis. It is also alleged that because so many frogs are killed for export to Europe, countries such as India are having to import chemical pesticides that would not otherwise be needed and which actually cost more than they receive for the butchered frogs.

Pesticides may also adversely affect frog spawning grounds, thus inhibiting population growth, as well as affecting the reproduction of birds of prey which normally live off rodents.

The conservationists believe that a ban on imports of frogs' legs into Europe would cut suppliers off from their markets and so destroy the incentive to hunt the frogs. Another possibility is that the edible frogs Rana tigerina and Rana hexadecatycla should be listed under the Convention on International Trade in Endangered Species, of which the Community is a signatory. But resistance from India, Bangladesh and Pakistan is so strong that this proposal may not even be tabled when the signatories to the convention meet in Buenos Aires in April.
Anna Lubinska 